EGU21-13101

https://doi.org/10.5194/egusphere-egu21-13101

EGU General Assembly 2021

(c) Author(s) 2021. This work is distributed under

the Creative Commons Attribution 4.0 License.

\title{
Rapid intensity variations during the second half of the first millennium BCE in Central Asia and global implications.
}

\author{
Raquel Bonilla-Alba ${ }^{1,2}$, Miriam Gómez-Paccard ${ }^{2}$, Francisco Javier Pavón-Carrasco ${ }^{1}$, Elisabet \\ Beamud $^{3}$, Verónica Martínez-Ferreras ${ }^{4}$, Josep Maria Gurt-Esparraguera ${ }^{4}$, Enrique Ariño-Gil ${ }^{5}$, Judit \\ del Rio ${ }^{2}$, Alicia Palencia-Ortas ${ }^{1,2}$, Fátima Martín-Hernández ${ }^{1,2}$, Annick Chauvin ${ }^{6}$, and María Luisa \\ Osete $^{1,2}$ \\ ${ }^{1}$ Complutense University of Madrid (UCM), Madrid, Spain \\ ${ }^{2}$ Institute of Geosciences IGEO (CSIC-UCM), Madrid, Spain \\ ${ }^{3}$ CCiTUB-Geo3Bcn, Geosciences Barcelona CSIC, Barcelona, Spain \\ ${ }^{4}$ University of Barcelona, Barcelona, Spain \\ ${ }^{5}$ University of Salamanca, Salamanca, Spain \\ ${ }^{6}$ University of Rennes
}

Recent archeomagnetic studies performed in different regions of the world have revealed unusual periods of sharp changes in intensity during the first millennium. Here we focus on the study of intensity variations between $600 \mathrm{BCE}$ and $600 \mathrm{CE}$ in central Asia, where an important intensity decrease seems to be present during the second half of the $1^{\text {st }}$ millennium BCE. For this purpose, we present a new paleosecular variation (PSV) curve obtained from 51 new archeointensities and the selected previous data located within a radius of $1000 \mathrm{~km}$ around Termez (Uzbekistan). The new curve shows an intensity maximum around 400 BCE followed by a rapid decrease. When the virtual axial dipole moment (VADM) values are compared with the Dipole Moment estimations derived from different global geomagnetic models key differences are observed, suggesting an important non-dipolar effect for this feature. Finally, in order to constrain the spatial behaviour of this phenomenon and its global implications, we investigate the PSV intensity and VADM trends from twelve regions distributed among Central America, Europe and Asia. A VADM maximum is observed in Western Europe (Iberia and Germany) around $450 \mathrm{BCE}$, associated to rates of change of about $9 \mu \mathrm{T} /$ century. This feature is also observed eastwards, in the Caucasus and the Levant, but associated to lower rates of changes. In Central Asia (Uzbekistan) our new study suggests that maximum values of about $14 \mu \mathrm{T} /$ century, between 400-300 BCE, were achieved. In other regions, as Eastern Asia and Central America, rapid variations of the intensity are not observed during the targeted period. 